\title{
Irrigation, lavage, colonic hydrotherapy: from beauty center to clinic?
}

\author{
G. Bazzocchi ${ }^{1} \cdot$ R. Giuberti ${ }^{2}$
}

Received: 4 November 2016/Accepted: 20 November 2016/Published online: 16 January 2017

(c) Springer International Publishing AG 2017

It is well known that in antiquity medicine often resorted to the use of enemas and rectoclysis to "free" the body of the "humors" and "poisons" believed to originate in the intestine and to cause diseases in many other organs. Indeed, an Egyptian papyrus dating back to the XVI century B.C. provides evidence of the belief that toxic substances produced by poorly digested foods could pass through the intestinal lumen and into the blood stream causing disorders even in distant organs. In the early 1900s a British surgeon, Sir William Arbuthnot Lane, was profoundly convinced of this theory: when the contents of the large intestine stagnate, "toxic substances" are more easily absorbed and lead to chronic disorders. As a result, he performed extensive colectomies on patients with a wide range of disorders: from arthritis to hypertension and skin pathologies. In those same years, the British Medical Journal published an article that concluded by saying that fecal stasis altered colon bacterial flora, thus favoring bacteria capable of toxin production (either anaerobes or coliforms) with systemic effects [1].

The concept of "autointoxication" as a cause of disease was later abandoned as modern medical research gained sway and did not produce proof supporting this theory; indeed, this topic incited heated debate in scientific circles. In 1997, "Colonic irrigation and the theory of autointoxication" was defined as "a triumph of ignorance over science" and those practicing it were deemed charlatans

G. Bazzocchi

bazzocchi@montecatone.com

1 Neurogastroenterology and Intestinal Rehabilitation, Montecatone Rehabilitation Institute, University of Bologna, Bologna, Italy

2 SICT Società Idrocolonterapia, Milano, Italy holding false and obsolete beliefs that masked economic interests [2].

Despite harsh criticism from the scientific community, the practice of colonic lavage has remained deeply rooted and the use of various instruments-from simple rectoclysis that operates by force of gravity to complex (and costly) colon hydrotherapy machinery-has continued to be widely accepted. Going even further, we can say that many patients request, and seek, this procedure and it is practiced by scores of doctors. Today, the slogan "clean on the inside-beautiful on the outside" has gained widespread support from, for instance, the world of fashion, the international jet set and the world of business. Centers have sprung up offering colon lavage both for esthetic reasons (it makes the skin lovelier!) and to achieve a general feeling of wellness, on a par with a wide selection of massages, baths, saunas and spa treatments. In the city of Milan alone, there are approximately 2000-3000 people who undergo colon hydrotherapy sessions at least once a month. This procedure is requested by people who believe it is good per se, but also by a large number of patients whose symptoms are associated with one or more bowel disorders, according to the Rome III Diagnostic Criteria that gastroenterology set up to organize itself at an international level, at least in terms of nosology and diagnostic behavior, in the mare magnum of symptoms that do not follow any precise and clear anatomical and pathological pattern.

The phenomenon is so widespread that the undeniable satisfaction perceived by those undergoing "intestinal lavage" must be taken into consideration: in other words, it cannot be simply the fruit of a campaign of misinformation supported by speculative interests and word-of-mouth indications based on ignorance. If nothing else, in view of this consideration, we must take a careful look at the idea 
that it is a useless, or even counterproductive, harmful procedure.

Moreover, some controlled studies have appeared comparing the effect of irrigation and lavage with conventional treatment approaches, in particular, for constipation and fecal incontinence which reap the greatest benefits both in terms of symptoms and quality of life [3-5]. These studies have used different irrigation methods and do not reflect an "impeccable" experimental design. However, beyond a shadow of a doubt, they do provide enough data to assert, as a recent Dutch study has done, that colonic irrigation is an effective treatment for untreatable defecation disorders [6] and for patients with functional disorders, as another paper concludes [7].

Moreover, some observations appear to indicate that mechanisms reminiscent of "autointoxication" may come into play. In one study of 57 patients with severe constipation, an immune activation condition was reflected by numerous indicators including elevated counts of CD3, CD4 and CD25, increased spontaneous proliferation of lymphocytes and increased ovoalbumin. Such activation tended to normalize when constipation was relieved with laxatives. The authors concluded that constipation is associated with striking changes in fecal flora, intestinal permeability and systemic immune response [8].

At the basis of the septic state so often found in intensive care patients, from the first step of SIRS systemic inflammatory response syndrome (SIRS) to the last step resulting in inexorable multiple organ failure (MOF), it appears that there is an overwhelming imbalance in the intestinal flora and the translocation of some strains through the mucosa with altered permeability [9]. A very recent paper confirms that intestinal dysbiosis is a common event in patients in intensive care units, and that it plays a role in septic complications [10]. Coprostasis, bacterial overgrowth, altered intestinal permeability, translocation and absorption of substances derived from inefficient digestive processes or from the metabolism of the altered flora themselves all come together to create a scenario which is now supported by a range of scientific evidence $[11,12]$.

One strong argument against intestinal lavage has always been the fact that the way this procedure works runs exactly counter to such proven treatments as the administration of dietary fiber and/or prebiotics and probiotics. On the one hand, the colon is "emptied" out while, on the other, the diet is supplemented with preparations that have a bulking effect which, in turn, stimulate the "production" of adequate colon contents, thus increasing fecal volume. We demonstrated that frequent, regular use of a steadypressure transanal irrigation procedure significantly improves constipation, incontinence scores and the QoL in a group of patients with "neurogenic bowel" resulting from spinal cord injury [13]. These patients have been using this technique for a few years now, some every other day and some every 3 days maximum. We constantly verify that their fecal output is normal in terms of both volume and consistency. This is in direct contrast with the conviction that lavage interferes with the development processes of normal intestinal microbiota, which is well known to be the main component of feces, making it difficult to maintain a suitable intraluminal environment for formation and transport of contents and thus forcing the patient to increasingly resort to the procedure. On the contrary, it is not unusual to find that, even after a single colon hydrotherapy session, the patient starts to improve, achieving evacuation that is satisfactory both in terms of frequency and completeness. This may be because, following treatment, the patient appears to better handle the administration of fiber, symbiotics and/or macrogol products which previously had caused abdominal discomfort and were thus taken only sporadically.

We can, however, speculate that this gradual, light methodical lavage, which can be extended for hours and repeated, can actually "free up" the large intestine, releasing fecal residues that were present for some time, stuck to the intestinal walls, obstructing transport, causing irritation and colon dysfunction. In summary, the regular use of colon cleaning techniques could, in individuals with serious intestinal motility problems, be an effective part of the stability of intestinal microbiota. Recent observations definitely support this idea that water use does not create imbalances, but rather improves dysbiosis [14].

Mechanical distension of the colon walls is the ideal mechanism for inducing high amplitude propagating contractions, the only colonic motor pattern able to ensure effective aboral transport of the endoluminal contents $[15,16]$. Modern transanal irrigation techniques also make it possible to bring adequate volumes of water to the more proximal colonic tracts, distending those sections. Hence, the subsequent evacuation is not simply the result of the action of the water per se, but also of induced propulsive motility. It is evident that the content of the ascending colon is also evacuated: post-irrigation studies with radiopaque markers have shown this to be true (Fig. 1) [17, 18].

In conclusion, there is adequate evidence based on convincing clinical data to re-examine the scientific community's total rejection of this method: rigorous studies must be performed on their short- and long-term effectiveness and also on the mechanisms of action involved in those pathologies that improve significantly thanks to lavage as a recent meta-analysis concludes [19].

Once again we may find that scientific evolution runs counter to prejudices and to final "judgements" with no right of appeal (Fig. 1). 


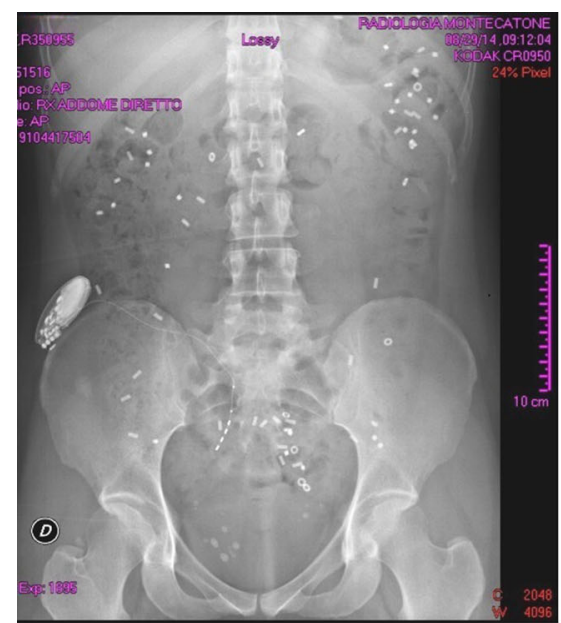

(a)

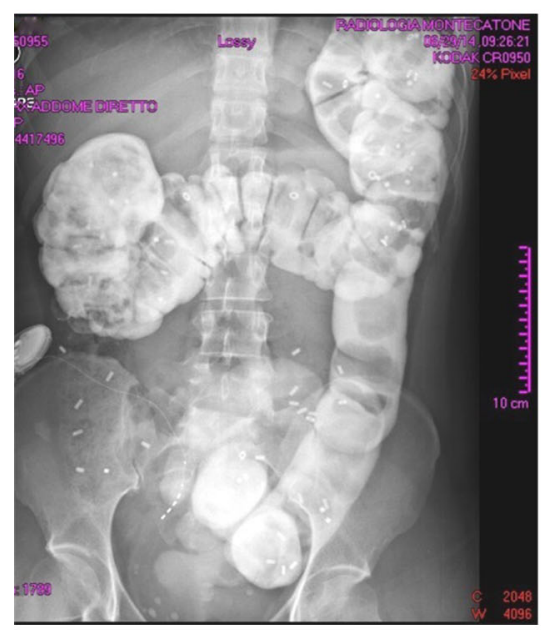

(d)

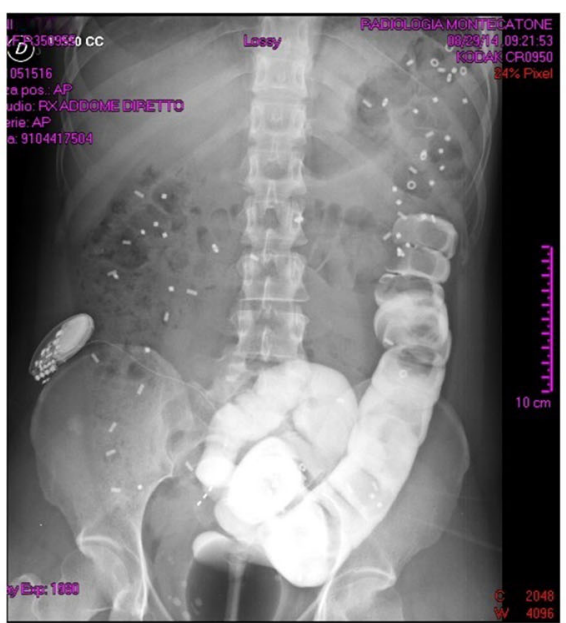

(b)

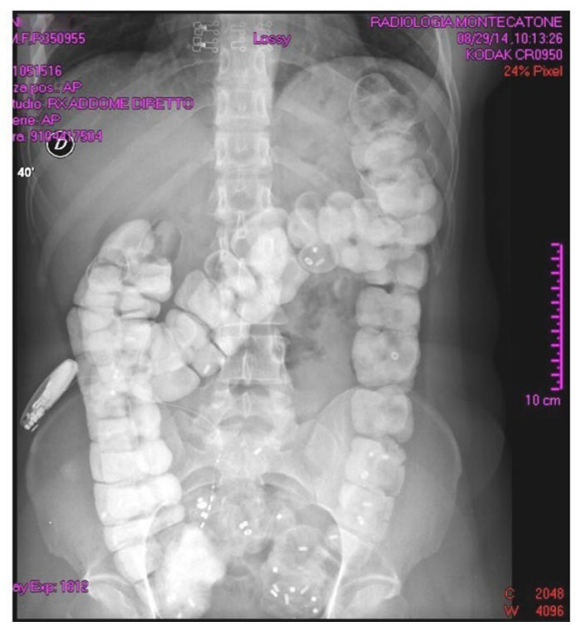

(e)

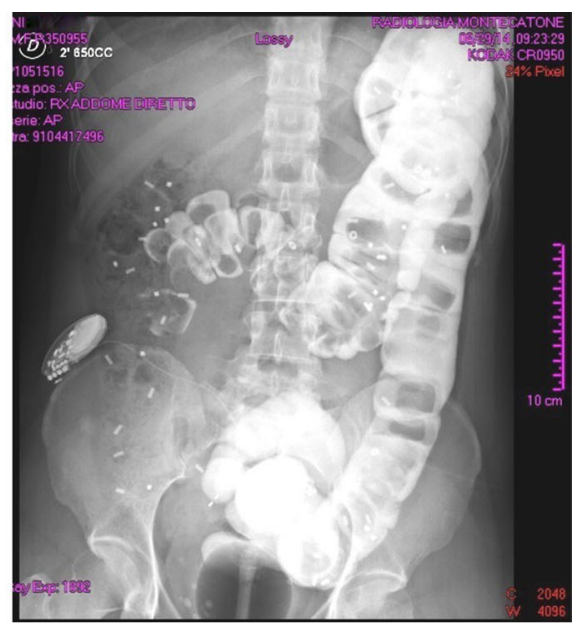

(c)

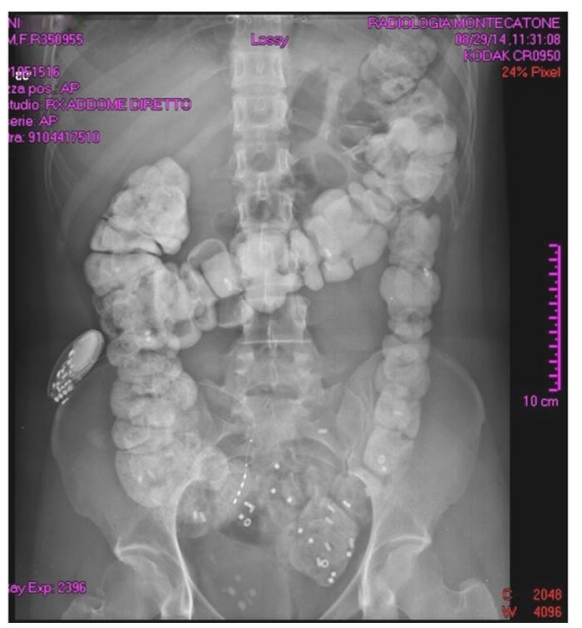

(f)

Fig. 1 A sequence of abdominal X-ray images taken during transanal irrigation. a Baseline, b 1 min after TAI started, $200 \mathrm{ml}$ water, c 2 min later, $450 \mathrm{ml}$ water, d $3 \mathrm{~min}$ later, $800 \mathrm{ml}$ water, probe removed, e $30 \mathrm{~min}$ later, after defecation, f $60 \mathrm{~min}$ later, after second defecation

A sequence of abdominal X-ray films is showing what happens in the colon of a patient with spinal cord injury during a session of transanal irrigation (TAI) using a device with a continent rectal catheter. After a radiopaque liquid (gastrografin) has been diluted in the water, irrigation is performed at the conclusion of an intestinal transit study with radiopaque markers. After 7 days, most markers are still retained along the entire large bowel. TAI starts after catheter balloon inflation: after only $1 \mathrm{~min}$, water has climbed into the descending colon. Interestingly, markers (and of course stools, where they are plunged) are pushed up, into the splenic flexure. After 2 min from the beginning of TAI, with the infusion of $450 \mathrm{ml}$ of water, the hepatic flexure is reached. When removing the probe, defecation occurs with expulsion of water and contents from the transverse colon and from the left colon. At the end, radiopaque markers which are present in the right colon are located in the sigmoid, and all the others are evacuated.

\section{Compliance with ethical standards}

Conflict of interest Gabriele Bazzocchi has served as an external consultant and advisory board member for Coloplast and has served as an advisory board member for Wellspect Health Care.

Ethical approval This article does not contain any studies with human participants or animals performed by any of the authors.

\section{References}

1. Ledingham JG (1913) The bacteriologic evidence of intestinal intoxication. Br Med J 1:821-823

2. Ernst E (1997) Colonic irrigation and the theory of autointoxication: a triumph of ignorance over science. J Clin Gastroenterol 24:196-198

3. Taffinder NJ, Tan E, Webb IG, McDonald PJ (2004) Retrograde commercial colonic hydrotherapy. Colorectal Dis 6:258-260

4. Crawshaw AP, Pigott L, Potter MA, Bartolo DCC (2004) A retrospective evaluation of rectal irrigation in the treatment of disorders of faecal continence. Colorectal Dis 6:185-190 
5. Gosselink MP, Darby M, Zimmerman DDE et al (2004) Longterm follow up of retrograde colonic irrigation for defaecation disturbances. Colorectal Dis 7:65-69

6. Koch SMP, Melenhorst J, van Gemert WG, Baeten CGMI (2008) Prospective study of colonic irrigation for the treatment of defaecation disorders. Br J Surg 95:1273-1279

7. Chan DS, Saklani A, Shah PR, Lewis M, Haray PN (2012) Rectal irrigation: a useful tool in the armamentarium for functional bowel disorders. Colorectal Dis 14:748-752

8. Khalif IL, Quigley EMM, Konovitch EA, Maximova ID (2005) Alterations in the colonic flora and intestinal permeability and evidence of immune activation in chronic constipation. Dig Liv Dis 37:838-849

9. Moore FA (1999) The role of the gastrointestinal tract in postinjury multiple organ failure. Am J Surg 178:449-453

10. McDonald D, Ackermann G, Khallova L et al (2016) Extreme dysbiosis of the microbiome in Critical Illness. mSphere 31:pii:e00199-16

11. Tilg H, Moschen AR (2015) Food, immunity, and the microbiome. Gastroenterology 148:1107-1119

12. De Giorgio R, Volta U, Gibson PR (2016) Sensitivity to wheat, gluten and FODMAPs in IBS: facts or fiction? Gut 65:169-178

13. Christensen P, Bazzocchi G, Coggrave M et al (2006) Treatment of fecal incontinence and constipation in patients with spinal cord injury: a prospective, randomized, controlled, multicenter trial of transanal irrigation vs conservative bowel management. Gastroenterology 131:738-747

14. Uchiyama-Tanaka Y (2012) The influence of colonic irrigation on human intestinal microbiota. In: Brzozowski $\mathrm{T}$ (ed) New advances in the basic and clinical gastroenterology. ISBN: 978-953-51-0521-3

15. Bassotti G, Gaburri M, Imbimbo BP, Morelli A, Whitehead WE (1994) Distension-stimulated propagated contractions in human colon. Dig Dis Sci 39:1955-1960

16. Bazzocchi G, Ellis J, Villanueva-Meyer J et al (1990) Postprandial colonic transit and motor activity in chronic constipation. Gastroenterology 98:686-693

17. Bazzocchi G, Poletti E, Pillastrini P, Menarini M (2006) Colonic emptying after a new transanal irrigation system in patients with spinal cord injury. J Spinal Cord Med 29:255

18. Bazzocchi G, Poletti E, Avogardi A (2012) L'irrigazione retrograda transanale per il bowel management del paziente con lesione midollare mediante dispositivi a pressione costante, razionale e procedura per l'utilizzo del Peristeen. Pelviperineology 31:85-92

19. Acosta RD, Cash BD (2009) Clinical effects of colonic clearing for general health promotion: a systematic review. Am J Gastroenterol 104:2830-2836 